\title{
Rapid Coprecipitation Technique Using Yttrium Hydroxide for the Preconcentration and Separation of Trace Elements in Saline Water Prior to Their ICP-AES Determination
}

\author{
Shigehiro Kagaya, ${ }^{\dagger}$ Satoshi Miwa, Toshiyuki Mizuno, and Koji ToHda \\ Graduate School of Science and Engineering for Research, University of Toyama, \\ Gofuku 3190, Toyama 930-8555, Japan
}

\begin{abstract}
Yttrium hydroxide quantitatively coprecipitated $\mathrm{Be}(\mathrm{II}), \mathrm{Ti}(\mathrm{IV}), \mathrm{Cr}(\mathrm{III}), \mathrm{Mn}(\mathrm{II}), \mathrm{Fe}(\mathrm{III}), \mathrm{Co}(\mathrm{II}), \mathrm{Ni}(\mathrm{II}), \mathrm{Cu}(\mathrm{II}), \mathrm{Zn}(\mathrm{II})$, $\mathrm{Cd}(\mathrm{II})$, and $\mathrm{Pb}(\mathrm{II})$ at $\mathrm{pH} 9.6-10.0$ for seawater and $\mathrm{pH} 10.5-11.4$ for a table-salt solution. The coprecipitated elements could be determined by inductively coupled plasma atomic emission spectrometry; yttrium was used as an internal standard element. The detection limits ranged from $0.001_{6} \mu \mathrm{g}(\mathrm{Mn}(\mathrm{II}))$ to $0.22 \mu \mathrm{g}(\mathrm{Zn}$ (II)) in $100 \mathrm{~mL}$ of sample solutions. The operation time required to separate 11 elements was approximately $30 \mathrm{~min}$.
\end{abstract}

(Received May 25, 2007; Accepted June 18, 2007; Published August 10, 2007)

It is important to determine trace elements in environmental samples from the viewpoint of environmental management and/or protection from hazardous infection ${ }^{1}$ as well as comprehension of the distribution of trace elements in the environment. ${ }^{2}$ Recently, multielement profiling analysis, in which major-toultratrace elements are determined and the distribution patterns of the elements are analyzed, has gathered attention to provide information about the elemental cycle in the environment. ${ }^{3,4}$

Inductively coupled plasma atomic emission spectrometry (ICP-AES) is a powerful method for multi-elemental analysis. ${ }^{5}$ For the determination of trace elements in environmental water samples, however, a preconcentration/separation technique is often required because of a lack of sensitivity and interference by matrices in the samples. ${ }^{5}$ Among various preconcentration/ separation techniques, coprecipitation with metal hydroxide is widely used for the ICP-AES determination of trace elements. ${ }^{6-23}$ In the coprecipitation method, however, the required quantitative separation of the precipitate is troublesome and time-consuming. To avoid such a quantitative separation prosess, a rapid coprecipitation technique has been proposed. ${ }^{23-29}$ In this technique, a carrier element used for coprecipitation also plays a role as an internal standard element. The carrier element is precipitated to coprecipitate trace elements in sample solutions. The precipitate is separated by using a decantation, short-time centrifugation, and so on; in this process, a part of the precipitate might be lost together along with a portion of the coprecipitated trace elements. However, the total amounts of trace elements in the sample solution can be determined by using the carrier element as an internal standard element, because the loss of trace elements is generally proportional to that of the carrier element.

Yttrium hydroxide ${ }^{30-32}$ has been used as a coprecipitant for the separation of some impurities, including $\operatorname{tin}^{30}$ and manganese ${ }^{31}$ in zinc and copper metals. It is of great advantage for trace elemental analysis that yttrium compounds with high purity are commercially available. Yttrium as a carrier element has an insignificant spectral interference for the ICP-AES determination

$\dagger$ To whom correspondence should be addressed.

E-mail: kagaya@eng.u-toyama.ac.jp of many elements. However, to our knowledge, no application of yttrium hydroxide to the preconcentration/separation of trace elements in environmental water samples has been reported.

In this work, we developed a preconcentration/separation method based on a rapid coprecipitation technique using yttrium hydroxide as a coprecipitant for the determination of trace elements in environmental water samples, especially saline water. In this method, 11 trace elements in $100 \mathrm{~mL}$ of saline water could be coprecipitated using a small amount of yttrium and a constant amount of sodium hydroxide solution. After separation and dissolution of the precipitate, the amount of trace elements could be determined by ICP-AES; yttrium could be used as an internal standard element. The developed method was simple and rapid, and was satisfactorily applicable to analyses of certified reference material and table salts.

\section{Experimental}

\section{Apparatus}

A Perkin Elmer Optima 3000DV inductively coupled plasma atomic emission spectrometer was used to measure elements. The emission intensity of each element was measured in the axial view mode at each wavelength summarized in Table 1; the other operating conditions were the same as those reported previously. ${ }^{23}$ The $\mathrm{pH}$ measurement was carried out by using a Horiba F-22 pH meter. A Kubota Model 5400 centrifuge was used for separating the precipitate.

\section{Reagents}

Purified water obtained by a Millipore Milli-Q purification system was used for all experiments. A yttrium solution (1 g $\left.\mathrm{L}^{-1}\right)$ was prepared by dissolving yttrium oxide $(99.99 \%$, Nacalai Tesque) in $5 \mathrm{~mL}$ of concentrated hydrochloric acid (for poisonous metal analysis, Kanto Chemical) and diluting to 100 $\mathrm{mL}$ with purified water. A commercially available ICP multielement standard solution XVI, which contains 21 elements including $\mathrm{Be}(\mathrm{II}), \mathrm{Ti}(\mathrm{IV}), \mathrm{Cr}(\mathrm{III}), \mathrm{Mn}(\mathrm{II}), \mathrm{Fe}(\mathrm{III}), \mathrm{Co}(\mathrm{II}), \mathrm{Ni}(\mathrm{II})$, $\mathrm{Cu}(\mathrm{II}), \mathrm{Zn}(\mathrm{II}), \mathrm{Cd}(\mathrm{II})$, and $\mathrm{Pb}(\mathrm{II})$ (100 $\mathrm{mg} \mathrm{L}^{-1}$ each, Merck), was 
Table 1 Analytical wavelengths, blank values, detection limits, and ranges of calibration curves for 11 elements

\begin{tabular}{cccc}
\hline Element & $\begin{array}{c}\text { Analytical } \\
\text { wavelength/nm }\end{array}$ & $\begin{array}{c}\text { Detection limit } \\
\mu g \text { in } 100 \mathrm{~mL}\end{array}$ & $\begin{array}{c}\text { Range of calibration } \\
\text { curve/ } \mu \mathrm{g} \text { in } 100 \mathrm{~mL}\end{array}$ \\
\hline $\mathrm{Be}$ & 313.107 & $0.001_{8}$ & $0.007-10$ \\
$\mathrm{Ti}$ & 334.940 & 0.032 & $0.10-10$ \\
$\mathrm{Cr}$ & 267.715 & $0.005_{4}$ & $0.02-10$ \\
$\mathrm{Mn}$ & 257.610 & $0.001_{6}$ & $0.015-10$ \\
$\mathrm{Fe}$ & 239.562 & 0.029 & $0.10-10$ \\
$\mathrm{Co}$ & 228.616 & $0.005_{5}$ & $0.015-10$ \\
$\mathrm{Ni}$ & 232.003 & 0.017 & $0.070-10$ \\
$\mathrm{Cu}$ & 224.700 & 0.080 & $0.20-10$ \\
$\mathrm{Zn}$ & 206.200 & 0.22 & $0.70-10$ \\
$\mathrm{Cd}$ & 228.802 & $0.006_{3}$ & $0.02-10$ \\
$\mathrm{~Pb}$ & 220.353 & 0.063 & $0.20-10$ \\
$\mathrm{Yb}$ & 371.030 & & \\
\hline
\end{tabular}

a. $3 \sigma(n=10)$.

b. Internal standard element.

used. The standard solution was diluted to a desired concentration in each experiment. The other reagents were of guaranteed or analytical reagent grade.

\section{Sample solutions}

For investigating the optimum conditions for coprecipitation, seawater and a table-salt solution was used as sample solutions. Seawater was sampled in Toyama Bay (Toyama, Japan); it was filtered through a membrane filter (Nihon Millipore, Omnipore membrane, pore size of $0.45 \mu \mathrm{m}$ ) before each experiment. A table-salt solution was prepared by dissolving $5.00 \mathrm{~g}$ of table salt (Ishikawa, Japan) with $100 \mathrm{~mL}$ of purified water. The appropriate amount of the standard solution containing trace elements was added to the seawater and table-salt solutions. For determining trace elements, 5.00 or $10.00 \mathrm{~g}$ of each table salt was dissolved with $100 \mathrm{~mL}$ of purified water.

\section{Procedure for separation of trace elements}

The sample solution $(100 \mathrm{~mL})$ was taken into (for seawater) or prepared in (for table-salt solution) a $175 \mathrm{~mL}$ of polystyrene centrifuge bottle (Nalgene). To the solution, $5 \mathrm{~mL}$ of a $2.0 \mathrm{~mol}$ $\mathrm{L}^{-1}$ nitric acid solution and $1 \mathrm{~mL}$ of a yttrium solution $\left(1 \mathrm{~g} \mathrm{~L}^{-1}\right)$ were added. A precipitate was formed after adding $3.7 \mathrm{~mL}$ of a $3 \mathrm{~mol} \mathrm{~L}^{-1}$ sodium hydroxide solution. The solution was allowed to stand for approximately $10 \mathrm{~min}$. After centrifugation at 3500 rpm for $5 \mathrm{~min}$, the supernatant solution was discarded. Purified water $(10 \mathrm{~mL})$ was added to the centrifuge bottle, which was then shaken by hand. The precipitate was re-centrifuged and dissolved with $5 \mathrm{~mL}$ of $1 \mathrm{~mol} \mathrm{~L}^{-1}$ nitric acid. The trace elements in these solutions were determined by ICP-AES; yttrium was used as an internal standard element. Solutions for blank tests and calibration curves were also prepared using $100 \mathrm{~mL}$ of purified water and purified water spiked with trace elements, respectively, in the same manner for the sample solution.

\section{Results and Discussion}

\section{Coprecipitation of trace elements with yttrium hydroxide}

Yttrium was quantitatively precipitated at a $\mathrm{pH}$ value of more than 11.1 from $100 \mathrm{~mL}$ of purified water spiked with $1 \mathrm{mg}$ of yttrium and $5 \mu \mathrm{g}$ of each trace element. It was found that $\mathrm{Be}(\mathrm{II}), \mathrm{Ti}(\mathrm{IV}), \mathrm{Cr}(\mathrm{III}), \mathrm{Mn}(\mathrm{II}), \mathrm{Fe}(\mathrm{III}), \mathrm{Co}(\mathrm{II}), \mathrm{Ni}(\mathrm{II}), \mathrm{Cu}(\mathrm{II})$, and $\mathrm{Cd}(\mathrm{II})$ were quantitative copreciptated (within $90-111 \%$ ) with yttrium hydroxide at $\mathrm{pH} 11.1$ - 12.1. Yttrium hydroxide also quantitatively coprecipitated $\mathrm{Zn}$ (II) and $\mathrm{Pb}$ (II) at $\mathrm{pH} 11.1$ 11.3; however, the recoveries of $\mathrm{Zn}$ (II) and $\mathrm{Pb}(\mathrm{II})$ decreased with increasing the $\mathrm{pH}$ above 11.3. In previous reports, yttrium hydroxide was used to coprecipitate some elements, including Sn and $\mathrm{Mn}$ in zinc and copper metals by adding aqueous ammonia for $\mathrm{pH}$ adjustments. ${ }^{30-32} \mathrm{Zn}$ (II) and $\mathrm{Cu}(\mathrm{II})$ were quantitatively coprecipitated in our investigations; this would be due to using a sodium hydroxide solution instead of aqueous ammonia.

Yttrium was also almost completely precipitated from $100 \mathrm{~mL}$ of seawater, and a table-salt solution at $\mathrm{pH}$ more than 9.6. Quantitative recoveries $(91-106 \%)$ were obtained for all 11 elements at $\mathrm{pH} 9.6-10.0$ for seawater and at $\mathrm{pH} 10.5-11.4$ for the table-salt solution. The difference in the $\mathrm{pH}$ ranges for the quantitative precipitation of yttrium and recoveries of trace elements by the different sample solutions was also reported for other coprecipitation systems. In coprecipitation with indium hydroxide, ${ }^{6}$ a quantitative precipitation of indium was achieved at a $\mathrm{pH}$ value above approximately 5.5 from artificial seawater, although the precipitation was insufficient at a $\mathrm{pH}$ value below approximately 7 from pure water. In gallium coprecipitation, ${ }^{13}$ precipitated gallium increased with increasing the concentration of magnesium ion in solution; the recoveries of trace elements also showed a strong dependence on the concentration of both gallium and magnesium in the solution. In our investigations, the contents of magnesium ions in $100 \mathrm{~mL}$ of the seawater and the table-salt solution were 72.4 and $5.8 \mathrm{mg}$, respectively. The $\mathrm{pH}$ ranges of the coprecipitation with yttrium hydroxide would be dependent on the concentration of some constituents, such as magnesium in the sample solutions.

In the coprecipitation method, a $\mathrm{pH}$ adjustment using a $\mathrm{pH}$ meter was sometimes cumbersome. To simplify the process of adjusting the $\mathrm{pH}$, a constant amount of $3 \mathrm{~mol} \mathrm{~L}^{-1}$ sodium hydroxide solution was added into the sample solutions as an operation in the proposed method. When $3.7 \mathrm{~mL}$ of the sodium hydroxide solution was added to $100 \mathrm{~mL}$ of purified water, seawater and a table-salt solution containing $5 \mathrm{~mL}$ of $2.0 \mathrm{~mol}$ $\mathrm{L}^{-1}$ nitric acid, $1 \mathrm{mg}$ of yttrium and $5 \mu \mathrm{g}$ of each trace elements, the solution $\mathrm{pH}$ was approximately $11.3,9.7$ and 10.7, respectively. In this case, the recoveries of all 11 trace elements were quantitative. Therefore, $3.7 \mathrm{~mL}$ of the sodium hydroxide solution was used for the $\mathrm{pH}$ adjustment.

The recoveries of the 11 trace elements reached within 93 $105 \%$ for approximately $10 \mathrm{~min}$ after formation of the precipitate. No significant change of the recoveries was observed when the solution was left standing for at least $4 \mathrm{~h}$.

\section{Application to rapid coprecipitation technique}

A carrier element used for the rapid coprecipitation technique must satisfy the following requirements: ${ }^{26-29}$ 1) the content of the carrier element in the sample solution must be negligibly small, 2) the carrier element added to the solution must be quantitatively precipitated, 3) the loss of the carrier element must be proportional to that of each trace element in the precipitate-separation process, and 4) the carrier element must be readily determined. In general, the yttrium background level in environmental water samples is negligible compared with the added yttrium in the proposed method $(1 \mathrm{mg})$. Yttrium could be quantitatively precipitated in $100 \mathrm{~mL}$ of the seawater, and the table-salt solution by adding $3.7 \mathrm{~mL}$ of the sodium hydroxide solution, and sensitively determined by ICP-AES. To verify that yttrium would meet the requirement 3), the relationship between the emission intensity of yttrium and that of each element after coprecipitation was investigated as follows. A part of the formed precipitate was discarded together with the 

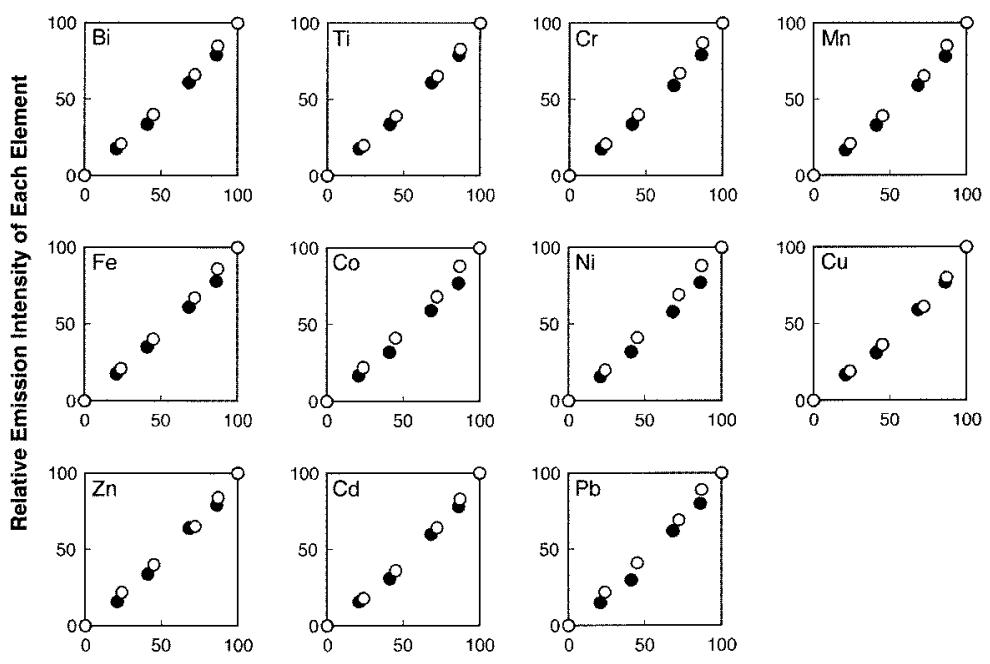

Relative Emission Intensity of $Y$

Fig. 1 Relationship between the emission intensity of yttrium and that of each element after coprecipitation. Sample solution, table-salt solution $(O)$ or purified water $(\bullet)$; sample volume, 100 $\mathrm{mL} ; 2.0 \mathrm{~mol} \mathrm{~L}-1 \mathrm{HNO}_{3}, 5 \mathrm{~mL}$; Y, $1 \mathrm{mg}$; each element, $5 \mu \mathrm{g} ; 3 \mathrm{~mol} \mathrm{~L}-1 \mathrm{NaOH}, 3.7 \mathrm{~mL}$.

Table 2 Removal of some matrix ions after coprecipitation and the centrifugation

\begin{tabular}{lcc}
\hline \multirow{2}{*}{$\begin{array}{c}\text { Matrix } \\
\text { ion }\end{array}$} & \multicolumn{2}{c}{ Content/mg } \\
\cline { 2 - 3 } & Sample solution $^{\mathrm{a}}$ & Solution after coprecipitation $^{\mathrm{b}}$ \\
\hline $\mathrm{Na}^{+}$ & 2950 & 0.2 \\
$\mathrm{~K}^{+}$ & 24 & N.D. \\
$\mathrm{Mg}^{2+}$ & 5.8 & 1.8 \\
$\mathrm{Ca}^{2+}$ & 4.6 & N.D. \\
\hline
\end{tabular}

a. A table salt (5.00 g) was dissolved with $100 \mathrm{~mL}$ of purified water. b. The solution was prepared according to the procedure for separation of trace elements described in the Experimental section.

N.D., Not detected.

mother liquor by decantation, and the remaining precipitate was collected by filtration. After dissolution of the precipitate, the yttrium and the trace elements were determined by ICP-AES. As shown in Fig. 1, linear relationships were obtained in all of the elements; that is, the loss of each trace element was proportional to that of the precipitate. Based on these results, it can be concluded that yttrium is applicable to the carrier element for the rapid coprecipitation technique.

The amounts of matrix ions removed by the proposed coprecipitation method are summarized in Table 2. Nearly $100 \%$ of sodium, potassium, and calcium ions in $100 \mathrm{~mL}$ of the table-salt solution were removed when the precipitate was washed with $10 \mathrm{~mL}$ of purified water after centrifugation at $3500 \mathrm{rpm}$ for $5 \mathrm{~min}$. Approximately $30 \%$ of magnesium contained in the table-salt solution was remained after washing; this was due to the lower solubility of magnesium hydroxide. Even in this case, the trace elements coprecipitated could be determined using yttrium as an internal standard element without any interference by magnesium.

\section{Calibration curves and detection limits}

Calibration curves, which are the relationships between the amounts of the trace elements and the emission intensity ratios of the trace elements to yttrium, could be prepared after coprecipitation using $100 \mathrm{~mL}$ of purified water spiked with the
Table 3 Results for the determination of 11 elements in a certified reference material, ES-L-1 (ground water)

\begin{tabular}{|c|c|c|c|c|c|}
\hline & $\begin{array}{l}\text { Found }^{\mathrm{a} /} \\
\mathrm{mg} \mathrm{L}^{-1}\end{array}$ & $\begin{array}{l}\text { Certified/ } \\
\mathrm{mg} \mathrm{L}^{-1}\end{array}$ & & $\begin{array}{l}\text { Found }{ }^{\text {a }} \\
\mathrm{mg} \mathrm{L}^{-1}\end{array}$ & $\begin{array}{l}\text { Certified/ } \\
\mathrm{mg} \mathrm{L}^{-1}\end{array}$ \\
\hline $\mathrm{Be}$ & $0.052 \pm 0.000_{3}$ & 0.052 & $\mathrm{Ni}$ & $0.010 \pm 0.000_{0}$ & 0.010 \\
\hline $\mathrm{Ti}$ & N.D. & - & $\mathrm{Cu}$ & $0.019 \pm 0.000_{3}$ & 0.020 \\
\hline $\mathrm{Cr}$ & $0.019 \pm 0.000_{2}$ & 0.020 & $\mathrm{Zn}$ & $0.020 \pm 0.000_{3}$ & 0.021 \\
\hline Mn & $0.099 \pm 0.001$ & 0.096 & $\mathrm{Cd}$ & $0.010 \pm 0.000_{1}$ & 0.010 \\
\hline $\mathrm{Fe}$ & $0.019 \pm 0.000_{3}$ & 0.021 & $\mathrm{~Pb}$ & $\left(0.002 \pm 0.000_{0}\right)^{\mathrm{b}}$ & $(0.002)^{\mathrm{c}}$ \\
\hline $\mathrm{Co}$ & $0.049 \pm 0.000_{3}$ & 0.051 & & & \\
\hline
\end{tabular}

a. Mean \pm standard deviation $(n=3)$.

b. The result was estimated by the extrapolation of the calibration curve. c. The value is not certified; it is listed for information only.

N.D., Not detected.

trace elements in the same manner as for the sample solution. Straight lines were obtained for all of the trace elements, as summarized in Table 1. Sub $\mu \mathrm{g} \mathrm{L}^{-1}$ levels of $\mathrm{Be}(\mathrm{II}), \mathrm{Cr}(\mathrm{III})$, $\mathrm{Mn}(\mathrm{II}), \mathrm{Co}(\mathrm{II}), \mathrm{Ni}(\mathrm{II})$ and $\mathrm{Cd}(\mathrm{II})$, and $\mu \mathrm{g} \mathrm{L}^{-1}$ levels of the other elements would be detected by combining the proposed coprecipitation method and ICP-AES.

The detection limits, which were defined as 3-times the standard deviations obtained from 10 replicate determinations of a blank solution after coprecipitation, are appended in Table 1. The blank values were $0.024 \pm 0.002 \mu \mathrm{g}$ (mean \pm standard deviation, $n=10$ ) for $\mathrm{Cr}(\mathrm{III}), 0.003 \pm 0.000_{5} \mu \mathrm{g}$ for $\mathrm{Mn}(\mathrm{II}), 0.18$ $\pm 0.01 \mu \mathrm{g}$ for $\mathrm{Fe}(\mathrm{III})$ and $0.038 \pm 0.006 \mu \mathrm{g}$ for $\mathrm{Ni}$ (II); the values for the other elements were less than the detection limits.

Determination of trace elements in certified reference material and table salts

To validate the proposed method, 11 elements in the certified reference material, EnviroMAT ${ }^{\mathrm{TM}}$ ground water (ES-L-1, SCP Science), were determined. As shown in Table 3, the obtained results were nearly equal to the certified values. The 11 elements in 2 kinds of table salts were also determined. As shown in Table 4, Cr(III), Mn(II), Fe(III), and Ni(II) could be detected. The recovery tests were also carried out using a solution spiked with the trace elements; all of the spiked 
Table 4 Results for the determination of 11 elements in table salts

\begin{tabular}{|c|c|c|c|c|c|c|c|}
\hline \multirow{2}{*}{ Element } & \multirow{2}{*}{$\begin{array}{c}\text { Added/ } \\
\mu \mathrm{g}\end{array}$} & \multicolumn{3}{|c|}{ Salt $1^{\mathrm{a}}$} & \multicolumn{3}{|c|}{ Salt $2^{b}$} \\
\hline & & Found ${ }^{c} / \mu \mathrm{g}$ & Conc./ $/ \mu g g^{-1}$ & Recovery, \% & Found $/ \mu \mathrm{g}$ & Conc. $/ \mu g g^{-1}$ & Recovery, \% \\
\hline \multirow[t]{2}{*}{$\mathrm{Be}$} & & $(0.009 \pm 0.001)^{\mathrm{d}}$ & $(0.002)$ & & $(0.014 \pm 0.002)^{\mathrm{d}}$ & $(0.001)$ & \\
\hline & 5 & $5.1 \pm 0.0_{6}$ & & 101 & $5.1 \pm 0.0_{8}$ & & 101 \\
\hline \multirow[t]{2}{*}{$\mathrm{Ti}$} & & N.D. & & & N.D. & & \\
\hline & 5 & $5.1 \pm 0.2$ & & 102 & $5.1 \pm 0.0_{4}$ & & 101 \\
\hline \multirow[t]{2}{*}{$\mathrm{Cr}$} & & $0.59 \pm 0.04$ & 0.12 & & $0.28 \pm 0.01$ & 0.028 & \\
\hline & 5 & $5.5 \pm 0.1$ & & 99 & $5.2 \pm 0.0_{4}$ & & 99 \\
\hline \multirow[t]{2}{*}{$\mathrm{Mn}$} & & $0.40 \pm 0.01$ & 0.080 & & $\left(0.037 \pm 0.000_{7}\right)^{\mathrm{d}}$ & $(0.004)$ & \\
\hline & 5 & $5.2 \pm 0.1$ & & 96 & $4.9 \pm 0.0_{1}$ & & 98 \\
\hline \multirow[t]{2}{*}{$\mathrm{Fe}$} & & $3.2 \pm 0.2$ & 0.65 & & $0.89 \pm 0.02$ & 0.089 & \\
\hline & 5 & $8.3 \pm 0.2$ & & 100 & $5.7 \pm 0.2$ & & 96 \\
\hline \multirow[t]{2}{*}{ Co } & & $(0.012 \pm 0.001)^{\mathrm{d}}$ & $(0.002)$ & & N.D. & & \\
\hline & 5 & $4.7 \pm 0.1$ & & 94 & $4.7 \pm 0.0_{1}$ & & 95 \\
\hline \multirow[t]{2}{*}{$\mathrm{Ni}$} & & $0.79 \pm 0.06$ & 0.16 & & $0.53 \pm 0.02$ & 0.053 & \\
\hline & 5 & $6.1 \pm 0.1$ & & 107 & $5.9 \pm 0.0_{3}$ & & 107 \\
\hline \multirow[t]{2}{*}{$\mathrm{Cu}$} & & N.D. & & & N.D. & & \\
\hline & 5 & $4.6 \pm 0.1$ & & 92 & $4.8 \pm 0.0_{4}$ & & 96 \\
\hline \multirow[t]{2}{*}{$\mathrm{Zn}$} & & N.D. & & & N.D. & & \\
\hline & 5 & $4.9 \pm 0.1$ & & 98 & $5.1 \pm 0.1$ & & 101 \\
\hline \multirow[t]{2}{*}{$\mathrm{Cd}$} & & N.D. & & & N.D. & & \\
\hline & 5 & $5.3 \pm 0.2$ & & 105 & $5.0 \pm 0.0_{1}$ & & 99 \\
\hline \multirow[t]{2}{*}{$\mathrm{Pb}$} & & N.D. & & & N.D. & & \\
\hline & 5 & $4.7 \pm 0.1$ & & 94 & $5.2 \pm 0.0_{3}$ & & 105 \\
\hline
\end{tabular}

a. Sample, $5.00 \mathrm{~g}$ in $100 \mathrm{~mL}$. b. Sample, $10.00 \mathrm{~g}$ in $100 \mathrm{~mL}$. c. Mean \pm standard deviation $(n=3)$. d. The result was estimated by the extrapolation of the calibration curve. Conc., Concentration; N.D., not detected.

elements were recovered within $10 \%$ error. The operation time required for separating the trace elements was approximately 30 min. These results indicate that the coprecipitation method will be useful for preconcentration/separation of the trace elements in environmental water samples, including saline water, and will also contribute to the analysis of table salt.

\section{Acknowledgements}

The authors are grateful for financial support from the Salt Science Research Foundation (No. 0604).

\section{References}

1. H. Haraguchi, J. Anal. At. Spectrom., 2004, 19, 5.

2. C. Turetta, G. Cozzi, C. Barbante, G. Capodaglio, and P. Cescon, Anal. Bioanal. Chem., 2004, 380, 258.

3. H. Haraguchi, Bull. Chem. Soc. Jpn., 1999, 72, 1163.

4. T. Yabutani, Bull. Soc. Sea Water Sci., Jpn., 2005, 59, 242.

5. C. Vandecasteele and C. B. Block, "Modern Methods for Trace Element Determination", 1993, John Wiley and Sons, Chichester.

6. M. Hiraide, T. Ito, M. Baba, H. Kawaguchi, and A. Mizuike, Anal. Chem., 1980, 52, 804.

7. A. S. Buchanan and P. Hannaker, Anal. Chem., 1984, 56, 1379.

8. R. Boniforti, R. Ferraroli, P. Frigieri, D. Heltai, and G. Queirazza, Anal. Chim. Acta, 1984, 162, 33.

9. K. Himeno, K. Yanagisawa, T. Yuki, and Y. Nakamura, Bunseki Kagaku, 1984, 33, T43.

10. T. Akagi, K. Fuwa, and H. Haraguchi, Anal. Chim. Acta, 1985, 177, 139.

11. T. Akagi, Y. Nojiri, M. Matsui, and H. Haraguchi, Appl. Spectrosc., 1985, 39, 662.

12. H. Daidoji, S. Tamura, and M. Matsubara, Bunseki Kagaku, 1985, 34,340 .
13. T. Akagi, K. Fuwa, and H. Haraguchi, Bull. Chem. Soc. Jpn., 1989, 62, 3823.

14. T. Akagi and H. Haraguchi, Anal. Chem., 1990, 62, 81.

15. P. Andersson and J. Ingri, Water Res., 1991, 25, 617.

16. H. Sawatari, E. Fujimori, and H. Haraguchi, Anal. Sci., $\mathbf{1 9 9 5}, 11,369$.

17. R. L. Adkins, N. Walsh, M. Edmunds, and J. M. Trafford, Analyst, 1995, 120, 1433.

18. H. Tsuji, N. Awano, Y. Tamari, K. Chayama, K. Teranishi, and K. Isomura, Bunseki Kagaku, 1995, 44, 471.

19. H. Sawatari, T. Hayashi, E. Fujimori, A. Hirose, and H. Haraguchi, Bull. Chem. Soc. Jpn., 1996, 69, 1925.

20. B. Ouddane, M. Skiker, J. C. Fischer, and M. Wartel, Analusis, 1997, 25, 308.

21. K. Morishige, M. Yoshida, T. Unuishi, and Y. Nishikawa, Bull. Soc. Sea Water Sci., Jpn., 2001, 55, 313.

22. V. Umashankar, R. Radhamani, K. Ramadoss, and D. S. R. Murty, Talanta, 2002, 57, 1029.

23. S. Kagaya, T. Sagisaka, S. Miwa, K. Morioka, and K. Hasegawa, Bull. Chem. Soc. Jpn., 2006, 79, 717.

24. S. Kagaya, Y. Hosomori, H. Arai, and K. Hasegawa, Anal. Sci., 2003, 19, 1061.

25. S. Kagaya, Z. A. Malek, Y. Araki, and K. Hasegawa, Anal. Sci., 2002, 18, 923.

26. S. Kagaya, Y. Araki, Y. Hori, and K. Hasegawa, J. Ecotech. Res., 2005, 11, 7.

27. S. Kagaya, Y. Araki, and K. Hasegawa, Fresenius J. Anal. Chem., 2000, 366, 842.

28. S. Kagaya, S. Kosumi, and J. Ueda, Anal. Sci., 1994, 10, 83.

29. J. Ueda and S. Kagaya, Bull. Chem. Soc. Jpn., 1992, 65, 1496.

30. K. Takeda, C. Akamatsu, and Y. Inoue, Fresenius' J. Anal. Chem., 1991, 339, 50.

31. K. Takeda, C. Akamatsu, and Y. Ishikawa, Anal. Chim. Acta, 1994, 298, 375.

32. T. Watabe and M. Nagaoka, Materia Japan, 1994, 33, 380. 